\title{
Implementasi Pembelajaran Daring Pada Mata Pelajaran Pendidikan Agama Islam Kelas IX di Sekolah Menengah Pertama Negeri 34 Padang
}

\author{
Muhamad Arif Anwar', Rini Rahman' \\ marifanwar1103@yahoo.com ${ }^{1}$, rinirahman@fis.unp.ac.id ${ }^{2}$ \\ Universitas Negeri Padang ${ }^{1,2}$
}

\begin{tabular}{|c|c|}
\hline ARTICLE INFO & ABSTRAK \\
\hline Article history: & \multirow{9}{*}{$\begin{array}{l}\text { Penelitian ini bertujuan untuk melihat } \\
\text { perencanaan, pelaksanaan dan kendala dalam } \\
\text { pembelajaran daring, juga melihat apakah yang } \\
\text { ditawarkan pihak sekolah untuk menyelesaikan } \\
\text { permasalah tersebut. Penelitan ini menggunakan } \\
\text { metode kualitatif dengan pendekatan study kasus. } \\
\text { Sumber data diambil dari } 8 \text { orang informan. Penulis } \\
\text { mengambil data melalui observasi dan dokumentasi. } \\
\text { Seluruh data wawancara dianalisis dengan cara } \\
\text { pengumpulan, reduksi, penyajian dan diakhiri dengan } \\
\text { pengambilan kesimpulan, secara keseluruhan hasil } \\
\text { penelitian mendapati bahwa, pertama, pada aspek } \\
\text { perencanaan pembelajaran pendidik menyiapkan } \\
\text { perangkat pembelajaran dengan sistem pembelajaran } \\
\text { daring, membuat program tahunan, program semester, } \\
\text { silabus, rencana pelaksanaan pembelajaran, minggu } \\
\text { efektif. Kedua, pada aspek pelaksanaan pembelajaran } \\
\text { darng yaitu bagaimana pelaksanaan pembelajaran } \\
\text { daring. Ketiga, pada aspek kendala dalam } \\
\text { pembelajaran daring didapati yaitu kendala kuota } \\
\text { pembelajaran daring, peserta didik menjadi kurang } \\
\text { memahami karena mengikuti pembelajaran dengan } \\
\text { satu gaya pembelajaran. }\end{array}$} \\
\hline Received 5 Agustus 2021 & \\
\hline Revised 24 Agustus 2021 & \\
\hline $\begin{array}{l}\text { Accepted } \\
2021\end{array}$ & \\
\hline$\overline{\text { Keyl }}$ & \\
\hline $\begin{array}{l}\text { Pembelajaran, Daring, } \\
\text { Pendidikan Agama Islam }\end{array}$ & \\
\hline & \\
\hline Fund & \\
\hline None & \\
\hline
\end{tabular}

Corresponding Author: Muhamad Arif Anwar, Department Islamic Education, Faculty of Social Science, Universitas Negeri Padang, Indonesia, Email: marifanwar1103@yahoo.com Phone: +628225173-6744

(c) $\underset{E Y}{(7)}$ Copyright(C2021, Author(s)

\section{Pendahuluan}

Pembelajaran pada masa pandemi Covid 19 saat ini menjadi penyebab dilakukannya pembelajaran daring, tentang pembelajaran daring sendiri sudah diatur dalam surat edaran Mendikbud nomor 4 tahun 2020 tentang pelaksanaan kebijakan Pendidikan dalam masa darurat penyebaran Covid 19. Pembelajaran daring 
merupakan pembelajaran yang menggunakan jaringan internet dalam kegiatan pembelajarannya. Maharani, dkk (2020) serta aplikasi seperti google class room, zoom meeting, edmodo dan aplikasi pembelajaran lainnya sebagai pendukung pembelajaran daring. Elianur (2020).

Peneltitian sebelumnya yang dilakukan oleh Wati tahun 2020 tentang Implementasi Pembelajaran Secara Daring Pada Mata Pelajaran Pendidikan Agama Islam Tingkat SMP Di Masa Pandemi Covid-19 yang di SMP Negeri 1 pariaman, berfokus kepada perencanaan pembelajaran daring, pengembangan model pembelajaran daring, pelaksanaan pembelajaran daring dan kendala dalam pembelajaran daring. tujuan dari penelitian ini yaitu untuk mengetahui perencanaan pembelajaran daring, pelaksanaan pembelajaran daring dan kendala pembelajaran daring.

Manfaat dari penelitian ini yaitu terbagi atas dua yaitu manfaat teoritis dari penelitian ini adalah untuk mengetahui dan memahami pendidik dalam bagaimana cara perencanaan pembelajaran daring, pelaksanaan pembelajaran daring dan kendala dalam pembelajaran daring. Serta kontribusi pengetahuan terhadap implementasi pembelajaran daring PAI di SMP Negeri 34 Padang. Manfaat Praktis yaitu bagi sekolah sebagai pengetahuan baru dan sumbangan pemikiran dalam memahami dan mengaplikasikan program pembelajaran daring pada pendidik dan peserta didik. Bagi penulis untuk mendapatkan gelar sarjana pada Jurusan Ilmu Agama Islam. Bagi masyarakat yaitu sebagai pengetahuan bagi masyarakat mengenai pembelajaran daring

\section{Tinjauan Pustaka}

Menurut Haryatna (2012) implementasi merupakan pelaksanaan/penerapan suatu program atau keyakinan hidup. Sedangkan pendapat yang disampaikan oleh Mulyasa (2009) bahwa implementasi merupakan suatu proses penerapan ide kebijakan, atau inovasi dalam suatu tindakan praktis sehingga memberikan dampak, baik berupa perubahan kognitif, afektif, psikomotorik dan sikap. Adapun implementasi sendiri merupakan proses penerapan suatu program yang merujuk kepada ide kebijakan dan tindakan yang praktis.

Pembelajaran daring ialah pembelajaran yang dilakukan dengan jarak jauh dengan bantuan internet dan didukung oleh sarana pembelajaran seperti handphone, laptop dan bantuan jaringan internet. Handarini, O. I., \& Wulandari, S. S. (2020) Adapun menurut Mukti tahun 2020, pembelajaran daring yaitu pembelajaran yang diartikan sebagai pembelajaran dengan menggunakan jaringan seperti internet, intranet dan lainnya dalam cakupan yang luas (Mukti, 2020:168).

Bentuk pembelajaran daring adalah E-Learning. (Electronic Learning). ELearning adalah metode pembelajaran online dengan aplikasi-aplikasi yang telah disediakan. Setiawan dkk (2021). Hal serupa disampaikan oleh Wilson (2020) Ada berbagai aplikasi pembelajaran yang tersedia di internet seperti 'Whatsapp Group', 'Google Classroom', 'Edmodo', 'Zoom', 'Google Meet', 'Webex', 'Loom', 'Quizizz', 
'Duolingo'. Peserta didik diajak mempelajari penggunaan aplikasi tersebut untuk terjalaninya proses pembelajaran pada masa pandemic covid 19 di rumah. Peserta didik juga belajar untuk meningkatkan kompetensinya baik bidang kognitif, psikomotorik, dan afektif.

Hal serupa juga disampaikan oleh Mubin (2021) bentuk dari pembelajaran daring PAI adalah Pertama. Visual Based Learing adalah pembelajaran daring dengan perangkat TI yang disempurnakan dengan aplikasi-aplikasi multimedia sehingga memudahkan pemahaman kepada peserta didik mengenai bentuk pembelajaran daring. Kedua. Diskusi Online adalah pembelajaran daring dengan aplikasi seperti Zoom dan Google Classroom yang dilakukan dengan video call secara Virtual dan diskusi mengenai materi lewat Google Classroom. Perencanaan adalah proses dan cara berfikir yang membantu membuat hasil yang diharapkan. Suatu perencanaan membutuhkan target yang akan dicapai, atau sebuah hasil yang harus dicapai. (Umaro, 2021:19).

Perencanaan pembelajaran daring meliputi penyusunan rencana pelaksanaan pembelajaran (RPP), penyiapan media dan sumber belajar, perencanaan penilaian pembelajaran, penyusunan rencana pelaksanaan pembelajaran, skenario pembelajaran, dan penyiapan media dan sumber belajar serta perangkat penilaian pembelajaran. (Wati, 2020: 138). Penyusunan perangkat pembelajaran bertujuan untuk memenuhi proses pembelajaran. Pertama Rencana, ialah bahan dan prosedur yang dibuat dalam suatu rencana khusus. Kedua saling ketergantungan, antara unsurunsur sistem pembelajaran yang serasi dalam suatu keseluruhan pembelajaran daring. Ketiga tujuan, sistem pembelajaran mempunyai tujuan tertentu yang hendak dicapai. (Hamalik, 2008).

Adapun berberapa kendala pembelajaran daring PAI yaitu ketidakpahaman orang tua terhadap pembelajaran daring, sinyal yang kadang tidak begitu bagus, orang tua yang menolak pembelajaran daring dengan alasan pembelajaran daring kurang meningkatkan pemahaman peserta didk dalam pembelajaran daring, orang tua tidak dapat menyelesaikan tugas bersama peserta didik bukan karena tidak paham namun karena kesibukan orang tua juga tidak sempat menjawab tugas peserta didik. (Harahap dkk, 2020: 94)

Menurut Ely Novianti, (2020) kendala pembelajaran daring yaitu seperti Fasilitas Gadget yang tidak semua peserta didik memiliki gadget tersebut menyebabkan pembelajaran terbagi menjadi dua bagian yaitu pembelajaran daring dan luring, yang dimana luring dengan melakukan jemput antar tugas sekolah dari sekolah ke rumah peserta yang dilakukan oleh peserta didik itu sendiri.

Penyebab kendala dalam pembelajaran daring yaitu Pertama, akses sinyal internet yang buruk. Dalam pembelajaran daring akses sinyal internet sangatlah penting, itu dikarenakan pembelajaran daringmemerlukan sinyal internet sebagai koneksi antara gadget peserta didik dengan gadget pendidik dalam pembelajaran daring. Kedua peserta didik kurang gesit dalam aktivitas pembelajaran. Karena materi yang disampaikan susah untuk dimengerti oleh peserta didik karena pendidik tidak menyampaikan secara langsung dipahami oleh peserta didik. Peserta didik tidak 
konsisten terhadap jadwal belajar. Ketiga banyak peserta didik yang tidak konsisten dalam pembelajaran karena pekerjaan membantu orang tua di rumah atau jadwal kegiatan harian peserta didik.

Hal yang menjadi kendala atau hambatan pertama adalah kondisi orang tua siswa yang lebih banyak menggunakan aplikasi WhatsApps (WA). Kendala yang kedua adalah kesulitan mencari jaringan internet dan gawai telepon pintar yang lebih sering dibawa orang tua yang bekerja. Aplikasi WA juga lebih mudah karena anak-anak banyak menggunakan dan bisa menggunakan. Kendala ketiga adalah kesulitan sinyal.

\section{Metodologi}

Metode yang digunakan dalam penelitian ini yaitu metode kualitatif dengan instrument seperti, wawancara, observasi, dan dokumentasi, yang dimana data primer dari penelitian ini yaitu kepala sekolah dan pendidik PAI di SMP Negeri 34 Padang, Adapun data sekunder atau data pendukung dari penelitian ini adalah Pendidik Kelas IX di SMP Negeri 34 Padang dan masyarakat di sekitar SMP Negeri 34 Padang.

Tahapan dalam metode penelitian ini yaitu melakukan wawancara kepada berberapa pendidik dengan data primer yaitu pendidik yang mengajar Pendidikan Agama Islam di SMP Negeri 34 Padang Yaitu Bapak Abdullah mengajar mata pelajaran PAI Kelas IX dan Pendidik PAI lain yaitu Bapak Aliber Hamzah yang mengajar kelas VIII dan Ibu Salmiati yang mengajar kelas VII. Data sekunder yaitu melakukan wawancara kepada pendidk-pendidik yang mengajar di kelas IX yang pertanyaannya seputar perencanaan pembelajaran daring kelas IX. Penulis juga melakukan observasi selama 11 Hari dari tanggal 1 April 2021 Hingga 11 April 2021 dengan melakukan observasi di sekolah terkait perencanaan pembelajaran daring PAI Kelas IX di SMP Negeri 34 Padang.

Teknik analisis data yang digunakan adalah Miles and Huberman. Menurut Miles and Huberman dalam mengemukakan bahwa aktivitas dalam analisis data kualitatif dilakukan secara interaktif dan berlangsung secara terus menerus sampai selesai, sehingga datanya kredibelitas. Aktivitas dalam analisis data, yaitu data reduction, data display, dan conclusion drawing/verification. (Sugiyono, 2016). Teknik pengabsahan data dalam penelitian ini adalahtriangulasi data. Triangulasi diartikan sebagai pengecekan data dari berbagai sumber dengan berbagai cara, dan berbagai waktu. (Sugiyono, 2016).

Setelah dilaksanakan kegiatan wawancara dan observasi maka penulis melakukan teknik analisis dalam metode penelitian kualitiatif serta teknik pengabsahan data dari penelitian yang telah dilakukan yaitu penelitian mengenai "Perencanaan Pembelajaran Daring PAI Kelas IX di SMP Negeri 34 Padang" 


\section{Hasil dan Pembahasan}

Pertama Perencanaan pembelajaran daring PAI dilakukan dengan pembekalan terhadap para pendidik. kemudian dilakukan kegiatan membuat RPP daring, prota, prosem, dan minggu efektif, dan membuat media pembelajaran di aplikasi pembelajaran seperti di Geschool. perencanaan pembelajaran terdiri dari rencana, dan tujuan yang hendak dicapai.

Berdasarkan penjelasan di atas sesuai dengan teori menurut Wati (2020) bahwa perencanaan pembelajaran daring dilakukan dengan mempersiapkan perangkat pembelajaran seperti RPP, prota (program tahunan), prosem (program semester), minggu efektif, skenario pembelajaran dan penyiapan media dan sumber pembelajaran dan perangkat penilaian pembelajaran. Adapun menurut Hamalik (2008) bahwa perencanaan pembelajaran daring terdiri dari tiga hal yaitu rencana, saling ketergantungan, tujuan, rencana adalah bahan dan prosedur yang harus dilakukan dalam membuat rencana pembelajaran daring. Saling ketergantungan artinya adalah setiap komponen perencanaan harus saling memiliki ketergantungan satu sama lain. Tujuan adalah bagaimana target dalam pembelajaran tersebut bisa tercapai dengan baik dan sempurna.

Kedua Pelaksanaan pembelaajran daring adalah kegiatan pembelajaran yang sudah terjadwal untuk dari dinas Pendidikan baik daring maupun luring. Pelaksanaan terbagi atas tiga yaitu pembukaan, pelaksanaan, penutup. Pembukaaan diawali dengan mengucapkan salam, mengisi dafrar hadir peserta didik dan penyampaian

tujuan pembelajaran. Pelaksanaan pembelajaran dilakukan dengan memberikan tugas kepada peserta didik melalui Geschool dan menjawab pertanyaan peserta didik jika kurang memahami tugas yang diberikan. Penutup dilakukan dengan pengumpulan tugas peserta didik melalui Geschool dan menyampaikan tema materi minggu selanjutnya dan pemberian PR (Pekerjaan Rumah).

Rombongan belajar di SMP Negeri 34 Padang dibagi menjadi dua kelas yaitu kelompok A belajar daring pada hari senin, rabu, jumat dan kelompok B belajar daring pada hari selasa, kamis, sabtu. Jumlah siswa juga dikurangi di dalam kelas yang berjumlah 32 orang menjadi 16 orang per kelas dengan jadwal pembelajaran daring yang telah ditentukan. Jam pembelajaran disekolah dibatasi yang awalnya adalah full day school yaitu sampai jam 16.00 sore kini berubah dari jam 07.00 sampai jam 12.00 siang dan hal ini berlaku untuk pembelajaran daring atau pembelajaran luring.

Berdasarkan penjelasan di atas sejalan dengan teori menurut Djamarah tahun 2015 dan Syaodih tahun 2006 tentang pelaksanaan pembelajaran daring dengan metode resitasi (Penugasan). Metode resitasi (penugasan) adalah metode penyajian bahan dimana pendidik memberikan tugas tertentu kepada peserta didik untuk dikerjakan sebagai metode pembelajaran. Tugas yang dilakukan oleh peserta didik dapat dilakukan di dalam kelas, di laboratorium, dan di perpustakaan. Djamarah (2015). Hal serupa juga disampaikan oleh syaodih bahwa metode ini dapat dilakukan dalam bentuk tugas atau kegiatan yang bersifat individual maupun kelompok dan 
merupakan unsur penting dalam pendekatan pemecahan masalah (problem solving) Syaodih (2006)

Ketiga mengenai kendala dalam pembelajaran daring PAI. Berberapa kendala pembelajaran daring yang dilakukan di SMP Negeri 34 Padang adalah pendidik yang belum mahir menggunakan Geschool dan peserta didik yang masih kongsi Gadget yang jadwal sekolah daringnya sama menyebabkan peserta didik tidak ikut kegiatan pembelajaran, Kurangnya pembelajaran secara face to face, sehingga peserta didik yang kurang jujur dalam mengerjakan tugas sering bermain game pada jam pelajaran, kurangnya pengawasan dari pendidik dan orang tua ketika melakukan pembelajaran daring dan mengobrol dengan teman melalui media sosial.

Penguasaan teknologi seperti Gadget dan laptop yang masih rendah, serta tidak semua orang mahir dalam menggunakan teknologi tersebut juga menjadi kendala dalam menjalankan proses pembelajaran secara daring pada peserta didik. Kendala lain yang ditemukan adalah adanya pemangkasan waktu belajar karena pengaruh kondisi pandemi, sehingga proses pembelajaran kurang efektif.

Berdasarkan penjelasan diatas sesuai dengan teori menurut Ely Novianti dkk tahun 2020 Keterbatasan sarana prasarana, terbatasnya sarana dan prasarana dalam pembelajaran menjadi kendala dalam pembelajaran daring, karena sarana dan prasarana yang memadai seperti aplikasi pembelajaran yang sesuai dengan gadget peserta didik agar pembelajaran dapat berjalan dengan baik. Kurangnya keefektifan pembelajaran daring yaitu ditandai dengan sulitnya menilai pada aspek sikap danketerampilan peserta didik karena pendidik kurang mengawasi pembelajaran peserta didik secara langsung.

Kurang melakukan budaya literasi artinya banyak dari peserta didik belum melakukan budaya literasi atau membiasakan membaca buku dan mengamalkannya karena faktor lingkungan yang tidak membiasakan membaca buku atau kurangnya motivasi belajar padahal dalam melakukan pembelajaran daring peserta didik dituntut untuk lebih banyak melakukan budaya literasi untuk memahami pembelajaran karena pembelajaran dilakukan dengan jarak jauh yang menyebabkan sulitnya pembelajaran karena gaya pembelajaran yang berbeda.

Hal ini sesuai dengan teori menurut Ely Novianti tahun 2020 yaitu bahwa tidak semua peserta didik memiliki gadget sehingga berkongsi dengan saudara. Hal serupa juga disampaikan oleh Anugrahana tahun 2020 Tidak semua peserta didik dapat mengikuti pembelajaran dengan fokus karena metode pembelajaran yang terkadang tidak sesuai dengan metode pembelajaran peserta didik tersebut. Teori tersebut juga didukung oleh harahap tahun 2020 yaitu bahwa akses jaringan yang lamban membuat peserta didik kurang memahami pembelajaran secara keseluruhan.

\section{Simpulan}

Berdasarkan Penelitian tentang Implementasi Pembelajaran Daring Pada Mata Pelajaran PAI Kelas IX di SMP Negeri 34 Padang yaitu terkait perencanaan 
pembelajaran daring PAI, pelaksanaan pembelajaran daring PAI, dan Kendala dalam pembelajaran daring PAI.

Pertama, perencanaan pembelajaran daring PAI tidak terlepas dari namanya peran pendidik dalam menguasai media teknologi pembelajaran dan persiapan perencanaan pembelajaran, yaitu menyusun RPP (Rancangan Pelaksanaan Pembelajaran) Silabus, Prota (Program Tahunan) Prosem (Program Semester) Minggu Efektif. Pada kenyataannya pendidik masih sedikit yang terampil dalam melakukan perencanaan pembelajaran dengan sistem daring, mengingat pendidik tidak semuanya terampil dalam menggunakan teknologi seperti membuat RPP dengan computer, laptop, dan aplikasi pembelajaran lainnya.

Kedua, pelaksanaan pembelajaran Daring PAI Kelas IX di SMP Negeri 34 Padang adalah dengan menggunakan aplikasi pembelajaran yaitu Geschool yang menjadi aplikasi wajib dari pemerintah dalam melakukan kegiatan pembelajaran daring. Bapak Abdullah, selaku pendidik yang mengajar PAI kelas IX menggunakan metode pembelajaran dengan sistem pemberian tugas, dan peserta didik juga menanya mengenai materi pembelajaran yang diberikan saat jam pelajaran berlangsung. Pembelajaran di SMP Negeri 34 Padang juga terbagi atas dua kelompok per kelas, kelompok pertama dengan nomor kehadiran 1-16 belajar luring pada hari senin-rabu dan daring pada hari kamis- sabtu, kelompok kedua belajar daring pada hari senin-rabu dan luring pada hari kamis-sabtu.

Ketiga, kendala dalam pembelajaran daring PAI di SMP Negeri 34 Padang adalah jaringan internet yang terkadang menganggu pembelajaran sehingga peserta didik tidak maksimal dalam mengikuti pembelajaran dengan baik. Peserta didik terkadang tidak serius dalam mengikuti pembelajaran karena pengawasan pendidik yang sedikit berkurang menyebabkan peserta didik lalai dalam mengumpulkan tugas. Pendidik hanya menggunakan satu gaya belajar yang menyebabkan peserta didik terkadang merasa bosan dalam mengikuti pembelajaran

\section{Referensi}

Anugrahana, A. (2020). Hambatan, Solusi dan Harapan: Pembelajaran Daring Selama Masa Pandemi Covid-19 Oleh Guru Sekolah Dasar. Scholaria: Jurnal Pendidikan dan Kebudayaan, 10(3), 282-289.

Djamarah, S. Bahri. 2015 Strategi Belajar Mengajar. Jakarta: Rineka Cipta,

Elianur, C. (2020). Pilihan Media Pembelajaran Daring Oleh Guru Pai Di Bengkulu Tengah.Jurnal As-Salam, 4(1), 37-45

Haryanta, Agung Tri. (2012) Kamus Kebahasaan dan Kesusasteraan Surakarta: Aksara Sinergi Media

Oeamar Hamalik.2008. Proses Belajar Mengajar (Jakarta: PT Bumi Aksara).

Handarini, O. I., \& Wulandari, S. S. (2020). Pembelajaran Daring Sebagai Upaya Study From Home (SFH) Selama Pandemi Covid 19. Jurnal Pendidikan Administrasi Perkantoran (JPAP), 8(3), 496-503. 
Harahap, A. S., Hafizhoh, N., Agustian, A., \& Utami, D. (2020). Pembelajaran PAI Berbasis Daring:(Studi Tentang Inovasi Pendidikan dalam Mengelola Media Pembelajaran di SMP Baitul Aziz Tembung).Jurnal Bilqolam Pendidikan Islam, 1(2), 82-97.

Maharani, A., Susanto, A., \& Mutiarani, M. (2020). Dinamika Pembelajaran Berbasis Daring Peserta Didik Kelas 9 SMP Muhammadiyah 19 Saat Pandemi. Seminar Nasional Penelitian 2020. LPJJ Jakarta: UMJ

Malyana, A. (2020). Pelaksanaan Pembelajaran Daring dan Luring Dengan Metode Bimbingan Berkelanjutan Pada Guru Sekolah Dasar Di Teluk Betung Utara Bandar Lampung. Pedagogia: Jurnal Ilmiah Pendidikan Dasar Indonesia, 2(1), 67-76.

Mubin, M. N. (2021). Pembelajaran Daring Pendidikan Agama Islam di Masa Pandemi Covid-19 di Sekolah

Menengah Sederajat. HEUTAGOGIA: Journal of Islamic Education, 1(1), 16-31. Mukti, M. P. W. (2020). Efektivitas Pembelajaran Daring Melalui Media Sosial pada Pelajaran Seni Musik di SMP 1 Jekulo Kudus. In Prosiding Seminar Nasional Pascasarjana (PROSNAMPAS) (Vol. 3, No. 1, pp. 167-174).

Mulyasa. (2009) Implementasi Tingkatan Satuan Pendidikan, Kemandirian Guru dan Kepala Sekolah. Jakarta: Bumi Aksara

Rusman. (2017). Belajar dan pembelajaran berorientasi standar proses pendidikan Jakarta: Kencana.

Setiawan, A. P., Masruri, L., Trastianingrum, S. A. P., \& Purwandari, E. (2021). METODE PEMBELAJARAN DARING AKIBAT COVID-19: PERSPEKTIF PELAJAR DAN MAHASISWA. Proyeksi: Jurnal Psikologi, 16(1), 83-91.

Surat Edaran Mendikbud No. 4 Tahun 2020 tetang Pelaksanaan Kebijakan Pendidikan dalam Masa Darurat Penyebaran Covid-19, 1 (2020). www.kemendikbud.go.id

Sugiyono. (2016). Metode Penelitian Kuantitatif, Kualitatif dan R\&D. Bandung: Alfabeta

Syaodih, Nana. 2006 Perencanaan Pengajaran. Jakarta: Rineka cipta,

Umaro, I. (2021). Problematika pembelajaran daring masa pandemi Covid-19 mata pelajaran Pendidikan Agama Islam (PAI) bagi peserta didik di SMP Negeri 23 Surabaya (Doctoral dissertation, UIN Sunan Ampel Surabaya).

Wati, N. W. I. (2020). Dampak Covid-19 Terhadap Implementasi Pembelajaran Berbasis Online (Daring) Di SMP Negeri 2 Kerambitan. WIDYALAYA: Jurnal Ilmu Pendidikan, 1(2), 253-260.

Wati S. (2020). Implementasi Pembelajaran Secara Daring Pada Mata Pelajaran Pendidikan Agama Islam Tingkat Smp Di Masa Pandemic Covid-19. Inovasi Pendidikan, 7(2).

Wilson, A. (2020). Penerapan Metode Pembelajaran Daring (Online) melalui Aplikasi Berbasis Android saat Pandemi Global.SAP (Susunan Artikel Pendidikan), 5(1). 